\title{
Resposta da Brachiaria brizantha cv. Marandu a fertilizantes nitrogenados associados ao fosfato natural reativo
}

\author{
Carlos Eduardo Avelino Cabral'*, Luciano da Silva Cabral', Edna Maria Bonfim-Silva², \\ Kassio dos Santos Carvalho3 ${ }^{3}$ Bruna Elusa Kroth², Carla Heloisa Avelino Cabral² \\ 'Universidade Federal de Mato Grosso, Cuiabá, MT, Brasil \\ ${ }^{2}$ Universidade Federal de Mato Grosso, Rondonópolis, MT, Brasil \\ ${ }^{3}$ Universidade de São Paulo, Piracicaba, SP, Brasil \\ *Autor correspondente, e-mail: carlos.eduardocabral@hotmail.com
}

\begin{abstract}
Resumo
Objetivou-se identificar uma proporção de ureia e sulfato de amônio associados ao fosfato natural reativo que maximize a produção do capim-marandu em Latossolo Vermelho de classe textural argilosa com baixo teor de fósforo. O experimento foi realizado em casa de vegetação, em delineamento experimental inteiramente casualizado, em esquema de parcelas subdivididas no tempo com sete repetições. As parcelas consistiram em seis níveis de substituição de ureia por sulfato de amônio: 0, 20, 40, 60, 80 e 100\%. As subparcelas consistiram em três períodos de crescimento, sendo o primeiro 30 dias após a emergência e os demais foram espaçados em 20 dias após a avaliação anterior. As variáveis avaliadas foram: número de perfilhos, valor SPAD, produção de matéria seca da parte aérea, lâminas foliares e colmo+bainha. O sulfato de amônio proporciona maior acidificação do solo do que a ureia, o que contribui para a solubilização de fosfato natural reativo. O incremento de sulfato de amônio altera o valor SPAD do capim-marandu quando adubado com fosfato natural reativo.
\end{abstract}

Palavras-chave: fósforo, Latossolo, sulfato de amônio, ureia

\section{Brachiaria brizantha $\mathrm{cv}$. Marandu response to nitrogen fertilizers associated to natural reactive phosphate}

\begin{abstract}
This study aimed to identify a proportion of urea and ammonium sulfate associated to natural reactive phosphate that coud maximize the production of 'marandu' grass in a red clayay oxisol with low phosphorus content. The experiment was conducted in a greenhouse with a completely randomized design, in split plots in the time with seven repetitions. The main plots consisted of six levels of the substitution of urea by ammonium sulfate: $0,20,40,60,80$ and $100 \%$. The split plots consisted of three growth periods, being the first 30 days after plants emergence and the others spaced 20 days after the previous evaluation. The evaluated variables were: number of tillers, SPAD value, shoot, leaf blade and stem dry mass. The ammonium sulfate can provide higher soil acidity when compared to urea, which contributes to the reactive phosphate solubilization. Ammonium sulfate increment changes the SPAD value of 'marandu' grass fertilized with natural reactive phosphate.
\end{abstract}

Keywords: phosphorus, oxisol, ammonium sulfate, urea 


\section{Introdução}

O fósforo é um nutriente limitante na implantação de gramíneas forrageiras, importante no estabelecimento de raízes (Mesquita et al., 2004; Cecato et al., 2008) e no restabelecimento radicular de gramíneas degradadas (Guedes et al., 2009). Para o suprimento de fósforo em pastagens implantadas no Brasil Central, onde há predomínio de Latossolos, a utilização de fontes solúveis é vantajosa pela disponibilidade instantânea desse nutriente. Contudo, esses fertilizantes apresentam custo elevado devido ao processo de industrialização, além de que parte do fósforo está sujeito à fixação no solo, o que reduz a disponibilidade às plantas (Lima et al., 2007).

Dessa forma, uma alternativa tem sido a utilização de fontes fosfatadas menos solúveis, tais como os fosfatos naturais reativos. Esses fertilizantes fosfatados podem minimizar a fixação de fósforo em solos intemperizados, além de reduzir o custo da adubação. A liberação gradual do fósforo proveniente do fosfato natural reativo é dependente da acidez do solo (Guedes et al., 2009), o que tem causado restrição no uso desses fertilizantes em solos pobres em fósforo, após a calagem. Uma alternativa tem sido a aplicação do fosfato natural antes da calagem, contudo tem-se observado a fixação do fósforo solubilizado, pois o nutriente permanece um longo período de contato com o solo e está sujeito a rápida sorção (Santos et al., 2011).

A adubação nitrogenada pode ser um recurso que permita o uso de fosfato natural reativo após a calagem, tendo em vista que o processo de nitrificação acarreta na redução natural do $\mathrm{pH}$ do solo. O nitrogênio é o nutriente mais requerido na adubação de manutenção de gramíneas forrageiras, o que pode viabilizar o uso de fosfato natural reativo na adubação dessas culturas. Dentre os fertilizantes nitrogenados, o sulfato de amônio resulta em maior acidificação do solo, comparativamente a ureia (Costa et al., 2008; Sousa \& Silva, 2009; Delbem et al., 2011), além de reduzir as perdas de nitrogênio por volatilização (Stafanato et al., 2013). Contudo, o uso de sulfato de amônio aumenta o custo da adubação, o que pode limitar a sua adoção pelos pecuaristas.
Dessa forma, a substituição parcial de ureia por sulfato de amônio pode viabilizar o uso de fosfato natural reativo na adubação de gramíneas forrageiras, tanto por atenuar a queda no pH do solo, quanto manter o custo de produção acessível, tendo em vista que a ureia é o fertilizante nitrogenado de menor custo. Das gramíneas forrageiras utilizadas no Brasil, o capimmarandu (Brachiaria brizantha cv. Marandu) é o mais expressivo, pois se observa mediana exigência em fertilidade, resistência à cigarrinha das pastagens e lenta redução do valor nutritivo pelo florescimento tardio. Assim, objetivou-se identificar uma proporção de ureia e sulfato de amônio associados ao fosfato natural reativo que maximize a produção do capim-marandu em Latossolo Vermelho de classe textural argilosa com baixo teor de fósforo.

\section{Material e Métodos}

O experimento foi realizado em casa de vegetação, em delineamento inteiramente casualizado, com sete repetições e em esquema de parcelas subdivididas no tempo. As parcelas consistiram em seis níveis de substituição de ureia por sulfato de amônio: 0, 20, 40, 60, 80 e 100\%. As subparcelas consistiram na avaliação de três períodos de crescimento, sendo o primeiro período avaliado 30 dias após a emergência do capim-marandu, e os demais períodos avaliados 20 dias após a avaliação anterior. As composições dos fertilizantes utilizados foram: fosfato natural reativo $\left(29 \%\right.$ de $\left.\mathrm{P}_{2} \mathrm{O}_{5} ; 32 \% \mathrm{Ca}\right)$, ureia $(46 \%$ de $N)$, sulfato de amônio $(21 \%$ de $N$, $24 \%$ de S) e cloreto de potássio ( $58 \%$ de $\mathrm{K}_{2} \mathrm{O}$ ). O fosfato natural reativo apresentava $14 \%$ de fósforo solúvel em ácido cítrico.

Cada unidade experimental foi constituída de um vaso com capacidade de 5,0 $\mathrm{dm}^{3}$ contendo cinco plantas. $O$ solo utilizado foi um Latossolo Vermelho de classe textural argilosa (Santos et al., 2013), coletado na camada de 0 a $20 \mathrm{~cm}$, em Cerrado nativo na região de Rondonópolis, Mato Grosso, cuja caracterização química e granulométrica (Tabela 1) foi realizada de acordo com a EMBRAPA (1997). Após a coleta, o solo foi peneirado em malha de $4 \mathrm{~mm} \mathrm{e}$ transferido para os vasos. Elevou-se a saturação por bases para 40\% (Vilela et al., 2004), com a 
incorporação de calcário dolomítico (PRNT = $80,3 \%$ ), que reagiu por 30 dias com a umidade do solo mantida a $80 \%$ da máxima capacidade de retenção de água no solo. Essa mesma umidade do solo foi mantida até o desbaste das plântulas, sendo em seguida elevada a $100 \%$ da máxima capacidade de retenção de água no solo.

Tabela 1. Caracterização granulométrica e química, com respectiva interpretação, de Latossolo Vermelho argiloso proveniente de Cerrado nativo.

\begin{tabular}{|c|c|c|c|c|c|c|c|c|c|c|c|c|}
\hline $\mathrm{pH}$ & $P$ & $\mathrm{~K}$ & $\mathrm{Ca}$ & $\mathrm{Mg}$ & $\mathrm{Al}$ & $\mathrm{H}$ & CTC & $\mathrm{V}$ & $\mathrm{m}$ & Areia & Silte & Argila \\
\hline $\mathrm{CaCl}_{2}$ & \multicolumn{2}{|c|}{$\mathrm{mg} \mathrm{dm}^{-3}$} & \multicolumn{5}{|c|}{$\mathrm{cmol}_{\mathrm{c}} \mathrm{dm}^{-3}$} & \multicolumn{2}{|c|}{$\%$} & \multicolumn{3}{|c|}{$\mathrm{g} \mathrm{kg}^{-1}$} \\
\hline 4,1 & 1,1 & 47 & 0,2 & 0,1 & 1,0 & 4,7 & 6,1 & 6,9 & 70,4 & 575 & 50 & 375 \\
\hline- & $M B$ & $M$ & $M B$ & $M B$ & - & - & $M$ & $M B$ & A & - & - & - \\
\hline
\end{tabular}

A máxima capacidade de retenção de água no solo foi realizada conforme descrito por Bonfim-Silva et al. (2011), com uma modificação no momento da drenagem dos vasos, ao qual os mesmos foram cobertos com plástico filme para evitar perdas por evaporação.

Após o período de incubação do solo com calcário para correção da acidez do solo foi feita a adubação de implantação, que consistiu na aplicação de fósforo e micronutrientes. A dose de fósforo $\left(\mathrm{P}_{2} \mathrm{O}_{5}\right)$ aplicada foi de $300 \mathrm{mg} \mathrm{dm}$ 3, utilizando fosfato natural reativo. A adubação básica com os micronutrientes foi efetuada com ácido bórico, cloreto de cobre, cloreto de zinco, molibdato de sódio nas doses de 1,5; 2,5; 2,0 e $0,25 \mathrm{mg} \mathrm{dm}^{-3}$, respectivamente (Bonfim-Silva \& Monteiro, 2010).

Depois da adubação de implantação realizou-se a semeadura do capim-marandu (Brachiaria brizantha cv. Marandu), com 25 sementes por vaso. Após a emergência foi feito o desbaste, deixando cinco plantas por vaso. O critério para o desbaste baseou-se no vigor e uniformidade das plântulas. Após o desbaste foi realizada a adubação nitrogenada e potássica $\left(\mathrm{K}_{2} \mathrm{O}\right)$, nas doses de 200 e $100 \mathrm{mg} \mathrm{dm}^{-3}$, sendo o nitrogênio fornecido conforme os tratamentos e o potássio na forma de cloreto de potássio. No primeiro crescimento a adubação com nitrogênio e potássio foi parcelada em quatro aplicações iguais para evitar uma pressão osmótica elevada, referenciada por Batista \& Monteiro (2008).

Trinta dias após a semeadura foi medido o valor SPAD (Soil Plant Analysis Development), realizada a contagem do número de folhas, perfilhos e o corte da parte aérea, que foi feito a $10 \mathrm{~cm}$ do solo. A leitura SPAD foi realizada com clorofilômetro portátil em cinco folhas diagnósticas por parcela experimental. As folhas diagnósticas correspondem as duas folhas mais novas e completamente expandidas. Foram contadas todas as folhas que estavam acima da altura de corte e todos os perfilhos presentes nos vasos.

Após o corte, a parte aérea foi separada em lâminas foliares e colmo+bainha, sendo essas frações acondicionadas em sacos de papel e submetidas à secagem em estufa de circulação de ar a $65^{\circ} \mathrm{C}$, até peso constante (Silva e Queiroz, 2002), e posteriormente pesadas. Além disso, foram retiradas amostras de solos para a determinação do pH em cloreto de cálcio, conforme descrito por EMBRAPA (1997). Todo o procedimento de leitura SPAD, contagem de folhas e perfilhos, corte das plantas e coleta de solo foi repetido na avaliação do segundo e terceiro crescimento, que ocorreu 20 dias após o corte anterior. Após cada corte foi reaplicada a adubação com nitrogênio e potássio, em doses de 200 e $100 \mathrm{mg} \mathrm{dm}^{-3}$, respectivamente, com as mesmas fontes já mencionadas.

As variáveis avaliadas foram: $\mathrm{pH}$ do solo, massa seca da parte aérea, lâminas foliares, colmo+bainha, número de perfilhos e valor SPAD (Soil Plant Analysis Development). Os resultados foram submetidos ao teste de Lilliefors (normalidade de resíduos) e Cochran (homogeneidade de variâncias). Diante da normalidade de resíduo e homogeneidade dos dados, procedeu-se à análise de regressão. A seleção do modelo adequado deu-se por meio do teste $\mathrm{F}$ e a significância dos componentes do modelo de regressão por meio do teste $t$, ambos a $5 \%$ de probabilidade de erro. 


\section{Resultados e discussão}

Independentemente do período de crescimento evidenciou-se que o número de perfilhos do capim-marandu foi descrito por um modelo linear crescente (Figura 1) quando o nitrogênio foi substituído gradativamente de ureia por sulfato de amônio.

Com o suprimento de sulfato de amônio, ocorre adição de enxofre, e esse nutriente influencia no perfilhamento de gramíneas forrageiras, observando-se efeito na rebrota de capim-marandu (Batista \& Monteiro, 2006). Além disso, o sulfato de amônio acidifica o solo (Costa et al., 2008), o que estimula a solubilização do fosfato natural reativo, e dessa forma, o fósforo também influencia a emissão de perfilhos de gramíneas forrageiras (Patês et al., 2007; Lopes et

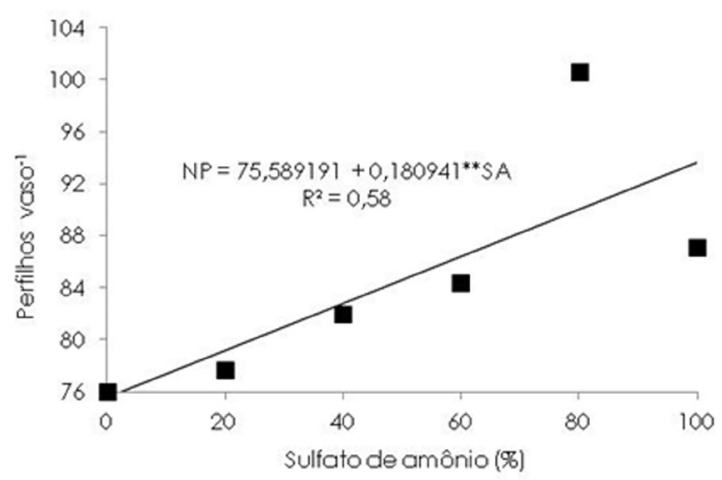

Figura 1. Estimativa do número de perfilhos (NP) do capimmarandu submetido a níveis de substituição de ureia por sulfato de amônio, independente dos períodos de crescimento. ** Significativo a $1 \%$ de probabilidade de erro pelo teste de $t$.

Além disso, a ureia é um fertilizante nitrogenado que está sujeito à perda de amônia $\left(\mathrm{NH}_{3}\right)$ por volatilização, que acarreta em quantidades menores de amônio $\left(\mathrm{NH}_{4}^{+}\right)$ disponível para nitrificação, processo que libera hidrogênios, acarretando na acidificação do solo (Barbosa Filho et al., 2005). Em vários trabalhos observa-se que a ureia propicia menor acidificação do que o sulfato de amônio (Costa et al., 2008; Sangoi et al., 2009; Sousa \& Silva, 2009).

No primeiro crescimento, o coeficiente angular da equação de $\mathrm{pH}$ do solo foi bem superior aos coeficientes do segundo e terceiro crescimento, o que indica que no estabelecimento do capim houve maior queda no pH com o incremento de sulfato de amônio al., 2011). O perfilhamento é relevante, uma vez que a emissão de folhas e perfilhos que garante a perenidade da gramínea forrageira.

$\mathrm{O}$ pH do solo, nos três crescimentos do capim-marandu, foi descrito por um modelo linear decrescente (Figura 2), o que indica que o aumento do sulfato de amônio no solo acarreta em maior acidificação do solo, comparativamente a ureia. A ureia, após a ação da urease, tem como um dos produtos a amônia $\left(\mathrm{NH}_{3}\right)$, e esta se associa a hidrogênios do solo no processo de redução a amônio $\left(\mathrm{NH}_{4}^{+}\right)$, gerando assim um aumento momentâneo do pH do solo. Kiehl (1989) verificou incremento no pH do solo após a aplicação da ureia de 4,8 a 6,6 e de 6,0 a 7,1 em Neossolo e Nitossolo, respectivamente.

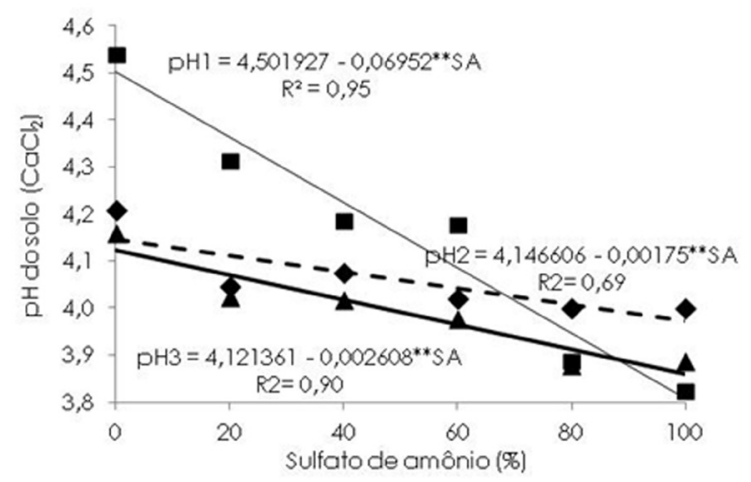

Figura 2. Estimativa da acidez ativa $(\mathrm{pH})$ do solo no primeiro $\left(\mathrm{pH}_{1}\right)$, segundo $\left(\mathrm{pH}_{2}\right)$ e terceiro $\left(\mathrm{pH}_{3}\right)$ crescimento do capimmarandu submetido a níveis de substituição de ureia por sulfato de amônio. ${ }^{* *}$ Significativo a $1 \%$ de probabilidade de erro pelo teste de $t$.

(Figura 2). A alteração no pH do solo influencia a solubilização do fosfato natural reativo, tendo em vista que esse fertilizante reage com prótons para a liberação do íon fosfato que é absorvido pelas plantas (Kaleeswari e Subramanian, 2001).

Durante o primeiro crescimento do capim-marandu, a produção de matéria seca de lâminas foliares, colmo+bainha a parte aérea foi diretamente proporcional ao incremento de sulfato de amônio na adubação nitrogenada (Figura 3). O aumento de sulfato de amônio na adubação do capim-marandu reduziu $\mathrm{o} \mathrm{pH}$ do solo (Figura 2), e essa condição propicia a solubilização do fosfato natural reativo (Goedert \& Lobato, 1984). Evidenciou-se que o pH do solo está associado a produção do capimmarandu, tendo em vista que houve correlação 
negativa significativa $(p<0,01)$ entre $\mathrm{pH}$ do solo e a massa seca de lâminas foliares $(r=-0,42)$, colmo+bainha $(r=-0,39)$ e parte aérea $(r=$ $-0,44)$. Resposta semelhante foi observada em estudo de solubilização de fosfato de Araxá, por meio do qual Souchie et al. (2007) observaram correlação negativa entre o pH e a solubilidade de fósforo.
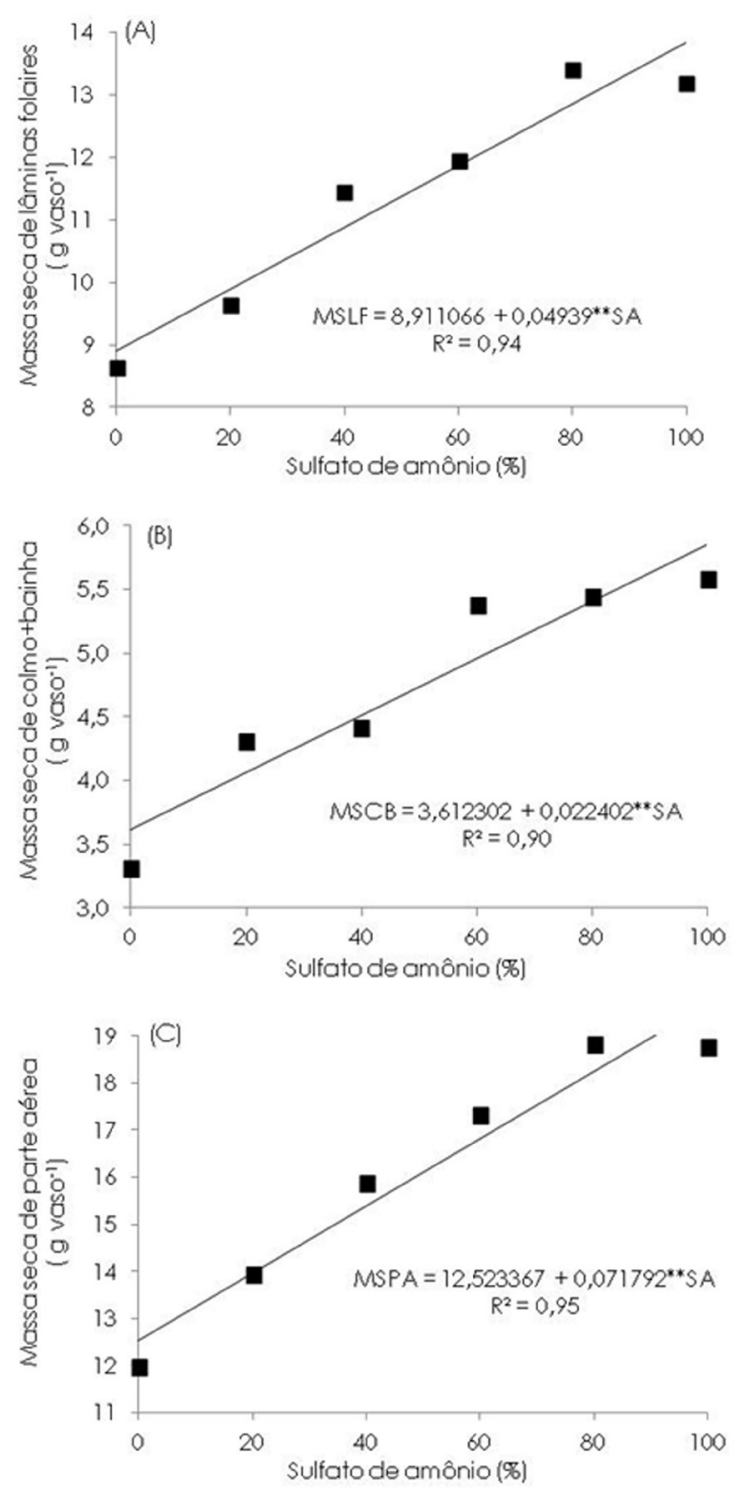

Figura 3. Estimativa da MSLV (massa de matéria seca de lâminas foliares - A), MSCB (massa seca de colmo+bainha - B) e MSPA (massa seca de parte aérea - C), no primeiro crescimento, do capim-marandu submetido a níveis de substituição de ureia por sulfato de amônio. ${ }^{* *}$ Significativo a $1 \%$ de probabilidade de erro pelo teste de $t$.

No segundo e no terceiro crescimento do capim-marandu, a produção de matéria seca não se ajustou a nenhum modelo de regressão. No segundo crescimento a massa seca de lâminas foliares, colmo+bainha e parte aérea observada no capim-marandu foram de 10,$1 ; 5,0$ e 15,1 g vaso- $^{-1}$, respectivamente. No terceiro crescimento a massa seca de lâminas foliares, colmo+bainha e parte aérea observada no capim-marandu foram de 14,8; 5,6 e 20,4 g vaso $^{-1}$, respectivamente.

Esperava-se que as proporções de ureia e sulfato de amônio tivessem efeito na produção do capim-marandu no segundo e terceiro crescimento, e não no primeiro, pois o nitrogênio é um nutriente mais requerido na rebrota de gramíneas forrageiras do que no estabelecimento (Cantarutti et al., 1999). Contudo, esses fertilizantes nitrogenados alteraram $\circ \mathrm{pH}$ do solo (Figura 2), e essa alteração na acidez ativa do solo influencia na solubilização do fosfato natural reativo (Guedes et al., 2009), que é uma fonte de fósforo. O fósforo é um nutriente de maior requerimento no primeiro crescimento de gramíneas forrageiras (Cantarutti et al., 1999), tendo em vista que seu papel principal está associado ao estabelecimento do sistema radicular. Por isso, os fertilizantes nitrogenados tiveram efeito sobre o primeiro crescimento e não sobre a rebrota do capim-marandu.

O valor SPAD (Soil Plant Analysis Development) do capim-marandu, nos três crescimentos, foi descrito por modelo quadrático (Figura 5). No primeiro, segundo e terceiro crescimento o nível de sulfato de amônio que propiciou maior índice SPAD no capim-marandu foi de 99,6; 57 e 41\%, respectivamente. O valor SPAD estima o teor de clorofila nas plantas e possui correlação positiva com o teor de nitrogênio (Manarim \& Monteiro, 2003), uma vez que de 50 a $70 \%$ do nitrogênio total das folhas serem integrantes de compostos associados aos cloroplastos e ao conteúdo da clorofila nas folhas (Chapman \& Barreto, 1997).

De acordo com Cabral et al. (2013), leituras SPAD em capim-marandu menores do que 26 indicam deficiência de nitrogênio, 0 que acarreta em clorose inicialmente nas folhas mais velhas e evolui para amarelecimento generalizado. Dessa forma, observa-se que independente da proporção entre ureia $e$ sulfato de amônio, não se observou valor SPAD que indicasse deficiência de nitrogênio nas plantas (Figura 5). 

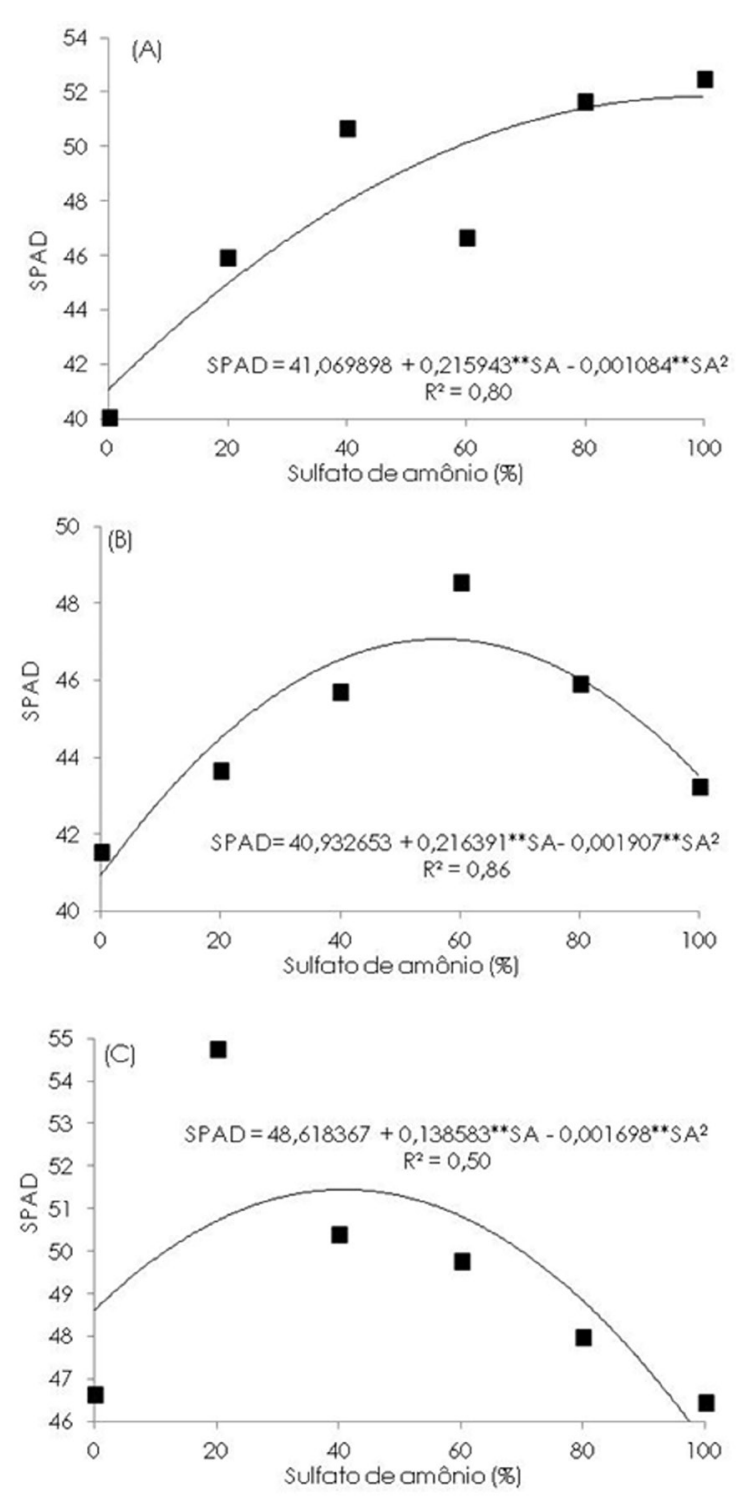

Figura 5. Estimativa do valor SPAD (Soil Plant Analysis Development) no primeiro (A), segundo (B) e terceiro (C) crescimento do capim-marandu submetido a níveis de substituição de ureia por sulfato de amônio. ** Significativo a $1 \%$ de probabilidade de erro.

\section{Conclusões}

O sulfato de amônio proporciona maior acidificação do solo do que a ureia, o que contribui para a solubilização de fosfato natural reativo.

$O$ incremento de sulfato de amônio altera o valor SPAD do capim-marandu quando adubado com fosfato natural reativo.

\section{Referências}

Barbosa Filho, M.P., Fageria, N.K., Silva, O.F. 2005. Fontes, doses e parcelamento da adubação nitrogenada em cobertura para feijoeiro comum irrigado. Ciência e Agrotecnologia 29: 69-76.

Batista, K., Monteiro, F. A. 2006. Respostas morfológicas e produtivas do capim-marandu adubado com doses combinadas de nitrogênio e enxofre. Revista Brasileira de Zootecnia 35: 1281-1288.

Batista, K., Monteiro, F.A. 2008. Nitrogênio e enxofre nas características morfogênicas do capim-marandu em substituição ao capimbraquiária em degradação em solo com baixo teor de matéria orgânica. Revista Brasileira de Zootecnia 37: 1151-1160.

Bonfim-Silva, E. M., Monteiro, F. A. 2010. Nitrogênio e enxofre na adubação e em folhas diagnósticas e raízes do capim-braquiária em degradação. Revista Brasileira de Zootecnia 39: 1641-1649.

Bonfim-Silva, E.M., Silva, T.J.A., Cabral, C.E.A., Kroth, B.E., Rezende D. 2011. Desenvolvimento inicial de gramíneas submetidas ao estresse hídrico. Revista Caatinga 24: 180-186.

Cabral, C.E.A.. Abreu, J.G.. Bonfim-Silva, E.M.. Cabral, C.H.A.. Scaramuzza, J.F.. Silva, T.J.A. 2013. Eficiência de produção e concentração de nitrogênio nos capins marandu, decumbens e convert submetidos à adubação nitrogenada. Bioscience Journal 29: 1653-1663.

Cantarutti, R.B.. Martins, C.E., Carvalho, M.M., Fonseca, D.M., Arruda, A.L., Vilela, H., Oliveira, F.T.T. 1999. Pastagens. In: Ribeiro, A.C., Guimarães, P.T. G. Alvarez V., V.H. (Eds). Recomendação para o uso de corretivos e fertilizantes em Minas Gerais. $5^{a}$ aproximação.CFSEMG, Viçosa, Brasil. p.43-60.

Cecato, U., Skrobot, V.D., Fakir, G.M., Branco, A.F., Galbeiro, S., Gomes, J.A.N. 2008. Perfilhamento e características estruturais do capim-Mombaça, adubado com fontes de fósforo, em pastejo. Acta Scientiarum Animal Sciences 30: 1-7.

Chapman, S.C., Barreto, H.J. 1997. Using a chlorophyll meter to estimate specific leaf nitrogen of tropical maize during vegetative growth. Agronomy Journal 89: 557-562.

Costa, K.A.P., Faquin, V., Oliveira, I.P., Rodrigues, C., Severiano, E.C. 2008. Doses e fontes de nitrogênio em pastagem de capim-marandu. I Alterações nas características químicas do solo. Revista Brasileira de Ciência do Solo 32: 15912599.

Delbem, F.C., Scabora, M.H., Soares Filho, C.V., Heinrichs, C., Crociolli, C.A., Cassiolato, A.M.R. 2011 . Fontes e doses de adubação nitrogenada na atividade microbiana e fertilidade do solo cultivado com Brachiaria brizantha. Acta Scientiarum. Agronomy 33: 361-367.

EMBRAPA - Empresa Brasileira de Pesquisa Agropecuária. 1997. Manual de métodos de análises de solo. Centro Nacional de 
Levantamento e Conservação do Solo. Embrapa Solos, Rio de Janeiro, Brasil. 212p.

Goedert, W.J., Lobato, E. 1984. Avaliação agronômica de fosfatos em solo de cerrado. Revista Brasileira de Ciência do Solo 8: 97-102.

Guedes, E.M., Fernandes, A.R., Lima, E.V., Gama, M.A.P., Silva, A.L.P. 2009. Fosfato natural de Arad e calagem e o crescimento de Brachiaria brizantha em Latossolo Amarelo sob pastagem degradada na Amazônia. Revista de Ciências Agrárias 52: 117-129.

Kaleeswari, R.K., Subramanian, S. 2001. Chemical reactivity of phosphate rocks - a review. Agricultural Reviews 22: 121-126.

Kiehl, J.C. 1989. Distribuição e retenção da amônia no solo após a aplicação de ureia. Revista Brasileira de Ciência do Solo 13: 75-80.

Lima, S.O., Fidelis, R.R., Costa, S.J. 2007. Avaliação de fontes e doses de fósforo no estabelecimento de Brachiaria brizantha cv. Marandu no sul do Tocantins. Pesquisa Agropecuária Tropical 37: 100-105.

Lopes, J., Evangelista, A.R., Pinto, J.C., Queiroz, D.S., Muniz, J.A. 2011. Doses de fósforo no estabelecimento de capim-xaraés e estilosantes Mineirão em consórcio. Revista Brasileira de Zootecnia 40: 2658-2665.

Manarim, C.A., Monteiro, F.A. 2003. Nitrogênio na produção e diagnose foliar do capim-mombaça. Boletim de Indústria Animal 59: 115-123.

Mesquita, E.E., Pinto, J.C., Furtini Neto, A.E., Santos, P.A., Tavares, V.B. 2004. Teores críticos de fósforo em três solos para o estabelecimento de capim-Mombaça, capim-marandu e capimandropogon em vasos. Revista Brasileira de Zootecnia 33: 290-301.

Patês, N.M.S., Pires, A.J.V., Silva, C.C.F., Santos, L.C., Carvalho, G.G.P., Freire, M.A.L. 2007. Características morfogênicas e estruturais do capim-Tanzânia submetido a doses de fósforo e nitrogênio. Revista Brasileira de Zootecnia 36: 1736-1741.

Sangoi, L., Ernani, P.R. Bianchet, O. 2009. Desenvolvimento inicial do milho em função de doses e fontes de nitrogênio aplicadas na semeadura. Biotemas 22: 53-58.

Santos, H.C., Oliveira, F.H.T., Salcedo, I.H., Souza, A.P., Silva, V.D.M. 2011. Kinetics of phosphorus sorption in soils in the state of Paraíba. Revista Brasileira de Ciência do Solo 35: 1301-1310.

Santos, H.G., Jacomine, P.K.T., Anjos, L.H.C., Oliveira, V.A., Lumbreras, J.F., Coelho, M.R., Almeida, J.A., Cunha, T.J.F., Oliveira, J.B. 2013.
Sistema brasileiro de classificação de solos. 3. ed. Embrapa, Brasília, Brasil. 353 p.

Silva, D.J., Queiroz, A.C. 2002. Análise de alimentos: métodos químicos e biológicos. 3. ed. UFV, Viçosa, Brasil. 235p.

Souchie, E.L., Abboud, A.C.S., Caproni, A.L. 2007. Solubilização de fosfato in vitro por microrganismos rizosféricos de guandu. Bioscience Journal 23: 53-60.

Sousa, R.A., Silva, T.R.B. 2009. Acidificação de um Latossolo Vermelho Distroférrico em função da aplicação de nitrogênio oriundo de ureia, sulfato de amônio e sulfammo. Cultivando o Saber, 2: 78-83.

Stafanato, J.B., Goulart, R.S., Zonta, E., Lima, E., Mazur, N., Pereira, C.G., Souza, H.N. 2013. Volatilização de amônia oriunda de ureia pastilhada com micronutrientes em ambiente controlado. Revista Brasileira de Ciência do Solo 37: 726-732.

Vilela, L., Soares, W.V., Sousa, D.M.G. 2004. Calagem e adubação para pastagens. In: Sousa, D. M. G., Lobato, E. Cerrado: correção do solo e adubação. 2. ed. Embrapa, Brasília, Brasil. p.367-382. 